\title{
Reverse-Phase High-Performance Liquid Chromatography of Hydrophobic Proteins and Fragments Thereof ${ }^{1}$
}

\author{
GEORGE E. TARR*,2 AND JOHN W. CRABB $\dagger^{* 3}$ \\ *Department of Biological Chemistry, University of Michigan, Ann Arbor, Michigan 48109, and \\ $\dagger$ Department of Ophthalmology, University of Washington, Seattle, Washington 98195
}

Received January 31, 1983

\begin{abstract}
Reverse-phase high-performance liquid chromatography (HPLC) resolution and recovery of cytochrome $P-450$ and bovine rhodopsin, both integral membrane proteins, and large peptides derived from $P-450 \mathrm{LM}_{2}$ were enhanced by utilizing ternary solvents. Surprisingly, most test materials eluted later in the gradient when using mixtures of acetonitrile and propanol in the mobile phase compared to using either solvent alone. Of the supports tested, the best recovery of hydrophobic cytochrome $P-450 \mathrm{LM}_{4}$ was experienced on the less retentive $\mathrm{CN}$-bonded phase. Two alternate solvents for HPLC of polypeptides are proposed: (1) 0.02-0.1 M hexafluoroacetone/ $\mathrm{NH}_{3}$, pH 7.2 for highly acidic peptides; and (2) $6 \mathrm{M}$ formic acid/0.13 $\mathrm{M}$ trimethylamine, $\mathrm{pH}$ 1.5 , vs $4 \mathrm{M}$ formic acid/0.09 $\mathrm{M}$ trimethylamine in propanol for relatively insoluble peptides. Anomalous side reactions between formic acid and peptides can cause HPLC peak broadening, increased retention, and decreased resolution. These deleterious effects are thought to be due in part to formyl esterification of serine and threonine residues and appear to be reversible by aminoethanol treatment.
\end{abstract}

High-performance liquid chromatography, particularly reverse-phase chromatography, has supplanted the more classical methods of peptide fractionation in many laboratories and constitutes one of the most important advances in the field of protein sequence analysis (1). The use of reverse-phase HPLC for the purification of small peptides is well established (1-2). However, larger peptides, especially those derived from membrane-associated proteins, often chromatograph poorly because of insolubility, aggregation, or irreversible adsorption to reverse-phase supports. Despite increasing reports of successful reverse-phase HPLC purification of large pep-

\footnotetext{
' Portions of this report were presented at the International Symposium on HPLC of Proteins and Peptides, held in Washington, D. C., November 16-17, 1981.

${ }^{2}$ To whom all correspondence should be addressed.

${ }^{3}$ Present address: Institut für Physiologische Chemie, Lehrstuhl I Ruhr-Universität, Universitätstrasse 150,4630 Bochum, West Germany.
}

tides (3-7) and hydrophobic, membrane-associated polypeptides (8-14), methods for such fractionations are not yet well established. This report incorporates the results of studies on types of reverse-phase supports and various solvent effects into methods which have enhanced the HPLC resolution and recovery of the integral membrane proteins cytochrome $P-450$ and bovine rhodopsin and of large peptides derived from $P-450 \mathrm{LM}_{2}$.

\section{MATERIALS AND METHODS}

Beckman Model 332 gradient HPLC systems were employed for all chromatography. Peptides and proteins in the column effluent were detected with either a Hitachi 100-10 spectrophotometer with an Altex flow cell or a Beckman 160 detector equipped with a Cd lamp and 229-nm filter. Peak areas were quantified with a Hewlitt-Packard Model $3380 \mathrm{~A}$ integrator or by cutting and weighing. The following reverse-phase HPLC columns 
were used: from Waters Associates, $\mu$ Bondapak $\mathrm{CN}, \mu$ Bondapak $\mathrm{C}_{18}, \mu$ Bondapak Phenyl $(30 \mathrm{~cm} \times 3.9 \mathrm{~mm}$ with $10-\mu \mathrm{m}$ packing); from Beckman, 5- $\mu \mathrm{m}$ Ultrasphere ODS $(25 \mathrm{~cm} \times 4.6 \mathrm{~mm})$; from The Separations Group, 5- $\mu \mathrm{m}$ Vydac $\mathrm{C}_{18}$ and $10-\mu \mathrm{m}$ Vydac $\mathrm{C}_{18}(25 \mathrm{~cm} \times 4.6 \mathrm{~mm}$ and $5 \mathrm{~cm} \times 4.6 \mathrm{~mm})$; from Alltech, $10-\mu \mathrm{m}$ Hamilton PRP-1 $(15 \mathrm{~cm}$ $\times 4.1 \mathrm{~mm}$ ). All columns contain a silica-based packing except the Hamilton PRP-1 which consists of a poly(styrene/divinylbenzene) matrix and all columns were packed by the manufacturer. Solvents were HPLC grade from Burdick and Jackson. Aminnethanol, formic acid, and cyanogen bromide were purchased from Aldrich and sequenal grade trifluoroacetic acid (TFA) ${ }^{4}$ from Pierce. Water was twice distilled. All chromatography was done at room temperature.

The hexafluoracetone (HFA) sesquihydrate used in these experiments came from three sources-Aldrich, DuPont, and PCR Research Chemicals. Unfortunately, because of its toxicity, none of these American companies presently offer this unique chemical although PCR has indicated that they may resume production. Sigma markets a HFA deuterate which appears to be an adequate substitute.

Commercially available proteins used as test materials included bovine ribonuclease (RNase, Worthington), bovine hemoglobin (Hb, Sigma), sperm whale myoglobin ( $\mathrm{Mb}$, Sigma), and bovine insulin (Sigma). Other test peptides included a basic 15-residue cyanogen bromide peptide from cytochrome $c$ designated $\mathrm{P} 15$, the dipeptide WE, the tetrapeptide PKGK, the hexapeptide LWMRFA, and the cyanogen bromide peptides of $\mathrm{Mb}$. Two homogeneous forms of rabbit liver microsomal cytochrome $P-450\left(\mathrm{LM}_{2}\right.$ and $\left.\mathrm{LM}_{4}\right)$ were kindly

\footnotetext{
${ }^{4}$ Abbreviations used: TFA, trifluoracetic acid; PTH, phenylthiohydantoin; $\mathrm{Mb}$, myoglobin; $\mathrm{Hb}$, hemoglobin; CB I, II, III, cyanogen bromide peptides of $\mathrm{Mb}$; SDS, sodium dodecyl sulfate; HFA, hexafluoroacetone; $\mathrm{MeCN}$, acetonitrile; $\mathrm{PrOH}$, propanol; ROS, rod outer segment membrane; Con A, concanavalin A; ODS, octadecylsilane.
}

provided by Dr. M. J. Coon (University of Michigan, Ann Arbor). The cytochrome $P$ $450 \mathrm{LM}_{2}$ and $\mathrm{LM}_{4}$ had been prepared as previously described (15) and contained small amounts of the nonionic detergent Renex. Delipidated bovine rhodopsin preparations were kindly provided by Dr. J. C. Saari (University of Washington, Seattle). Outer segment membranes of bovine retinal rods (ROS) were isolated essentially as described by $\mathrm{Pa}$ permaster and Dreyer (16). Purified ROS were delipidated by affinity chromatography on Con A-Sepharose according to De Grip et al. (17) using Chaps as the detergent. Standard methods were used for cyanogen bromide cleavage of cytochrome $P-450$ and Mb (18) and for performic acid oxidation of insulin and RNase (16).

Relative recoveries were calculated from peak areas recorded and integrated at 214 or $229 \mathrm{~nm}$, with adjustment for flow rate. Absolute recoveries were determined by amino acid analysis of individual test solutions and peaks collected. N-terminal amino acid sequence analyses (20) and PTH-amino acid identifications (21) were done according to Tarr.

\section{RESULTS}

\section{HPLC of Large Hydrophobic Polypeptides and Ternary Solvent Effects}

Chromatography of the integral membrane protein cytochrome $P-450 \mathrm{LM}_{2}$ is shown on several reverse-phase supports in Fig. 1. Of particular interest is the resolution into a minor and major, more hydrophobic, component (Fig. 1). As these two forms have the same molecular weight by SDS-polyacrylamide gel electrophoresis, the same amino acid compositions and the same $\mathrm{N}$-terminal sequence, one is presumably a secondary modification of the other. The chromatographic patterns of $P-450$ and solvent effects vary between columns. With acetonitrile as eluting solvent all except the $\mu$ Bondapak $\mathrm{CN}$ separate at least partially the major and minor forms of $P-450$ (Fig. 2). Retention of the membrane 


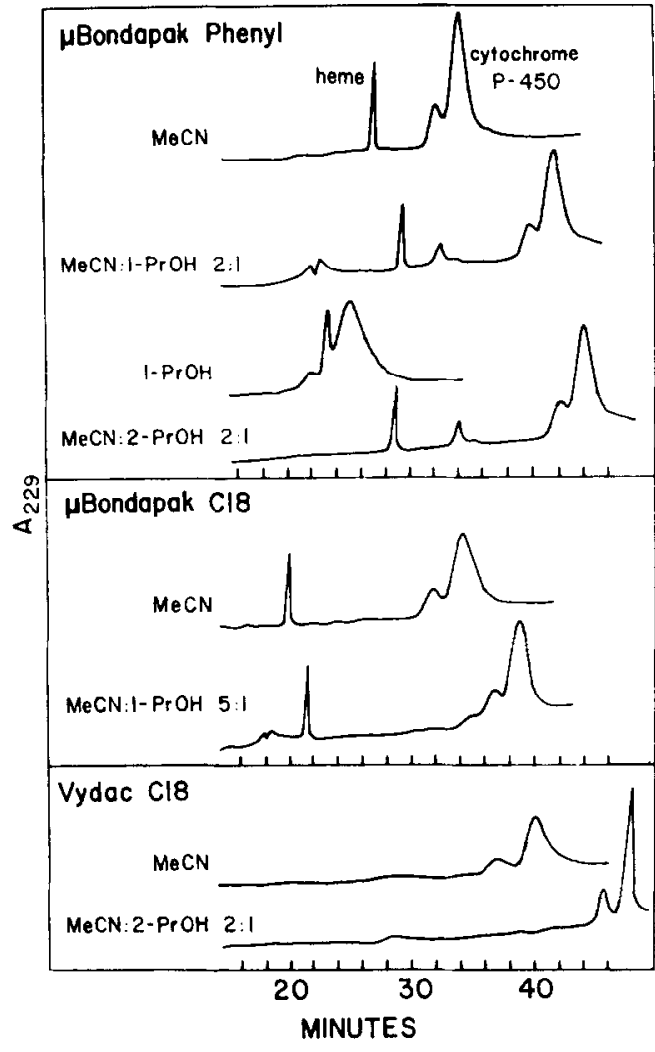

FIG. 1. HPLC of holocytochrome $P-450 \mathrm{LM}_{2}$ on selected reverse-phase supports. About $1 \mathrm{nmol}$ of freshly acidified protein was injected in $40 \mu \mathrm{l}$ at $0 \%$ organic. All eluting solvents contained $0.1 \%$ TFA; the organic components are indicated. Flow rates were $0.7 \mathrm{ml} / \mathrm{min}$ ( $\mu$ Bondapak) and $1 \mathrm{ml} / \mathrm{min}$ (Vydac) in order to approximate constant linear velocity; following a programmed jump to $40 \%$ organic at $2 \mathrm{~min}$, a linear gradient of $1 \% \mathrm{ml} / \mathrm{min}$ was used in each case. Absorbance was monitored at 229 nm, 1.0 AUFS.

proteins is shortest on the $\mu$ Bondapak $\mathrm{CN}$ column and longest on the large pore Vydac C18; the separation of heme and protein is least on the $\mu$ Bondapak Phenyl column and greatest on the Vydac C18. These are all effects that may be expected from the relative hydrophobicity and aromaticity of the bonded phases and from the degree a large protein may interact with the bonded phase in smaller vs larger pore silica.

Ternary gradients have proven useful for the separation of complex mixtures of small molecules with considerable improvement in resolution over binary solvent systems (22). The effect of ternary solvent systems in our separation of a standard test mixture of peptides and proteins composed of RNase, $\mathrm{Mb}$, B-chain insulin, and cyanogen bromide peptides of $\mathrm{Mb}$ was dramatic but unexpected (results to be published elsewhere). Nearly all test materials eluted later when 2-propanol was added to the acetonitrile, this despite the well-documented greater eluting power of propanol relative to acetonitrile (7). In fact, retention time appears to go through a maximum as the proportion of propanol in the acetonitrile is gradually increased, until at roughly $1: 1(\mathrm{v} / \mathrm{v})$ the retention time has returned again to that seen with acetonitrile alone. Increasing amounts of propanol invariably broadened the peaks, though at lower proportions (2-5:1), this was more than compensated by the spreading out of the effective separation range. On the $\mu$ Bondapak columns (120 А, average pore diameter) cytochrome $P-450 \mathrm{LM}_{2}$ was affected by propanol/acetonitrile mixtures like the smaller and more hydrophilic standards; however, on the Vydac column (300 $\AA$, pore), while retention was again increased, the peaks were dramatically sharpened (Fig. 1). This may reflect improved solubility, as this wider pore support required a higher concentration of organic solvent for elution.

Recoveries of $P-450 \mathrm{LM}_{2}$ from $\mu$ Bondapak and Vydac columns were similar, with about $2 / 3$ of the injected protein eluting in the two peaks described above; we have evidence that more protein elutes broadly after the main peak although we cannot rule out that some is stuck irreversibly. The $\mathrm{LM}_{4}$ isozyme is much more readily precipitated by organic solvents than $\mathrm{LM}_{2}$ (15), which presumably accounts for the much better recovery of $\mathrm{LM}_{4}$ (comparable to that for $\mathrm{LM}_{2}$ ) from the least retentive column, the $\mu$ Bondapak CN (Fig. 2).

Reverse-phase chromatography of the cyanogen bromide peptides of cytochrome $P$ $450 \mathrm{LM}_{2}$ under various solvent conditions is shown in Fig. 3. Although there are only eight methionine residues in the protein, partial acid 


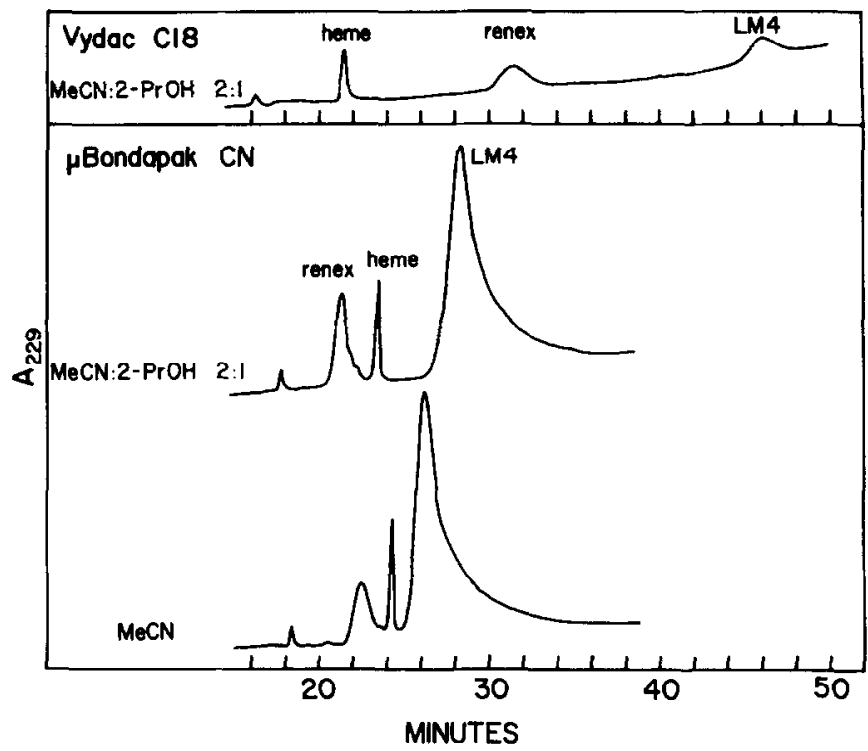

FIG. 2. Reverse-phase HPLC of holocytochrome P-450 $\mathrm{LM}_{4}$. Quantitics and conditions same as in Fig. 1.

cleavage of the five Asp-Pro linkages during the cyanogen bromide reaction gives a very complicated peptide mixture. A ratio of 3:1 acetonitrile:propanol $(\mathrm{v} / \mathrm{v})$ gave increased retention of all peptides, but also better recovery of the most hydrophobic ones. While aceto-

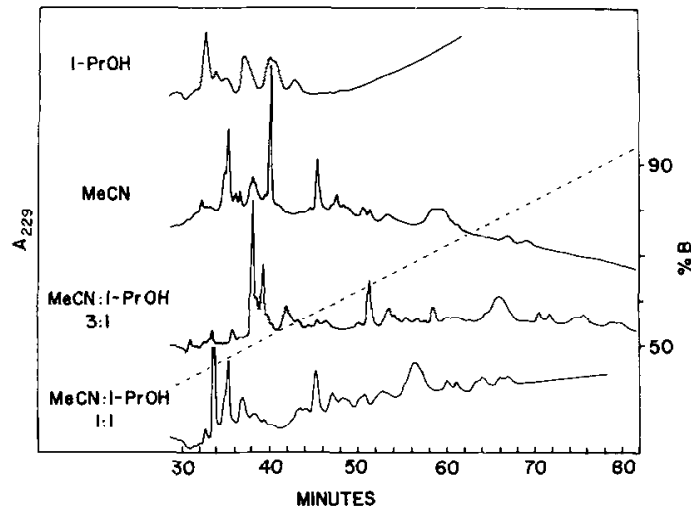

FiG. 3. Comparison of the HPLC of a cyanogen bromide digest of cytochrome $P-450 \mathrm{LM}_{2}$ under various solvent conditions. All separations were performed on a $\mu$ Bondapak $C_{18}$ column at a flow rate of $0.7 \mathrm{ml} / \mathrm{min}$ in a $1 \%$ linear gradient. Note improved chromatography in terms of resolution and recovery of late-eluting peptides with $\mathrm{MeCN}$ :PrOH mixtures relative to either acetonitrile or propanol alone. nitrile alone ceased to elute effectively above about $80 \%$, the $3: 1$ mixture continued to elute peptides above $90 \%$, sharpening the latest peaks seen with acetonitrile and eluting more hydrophobic peptides not seen previously. At $1: 1$ the various peptides roughly returned to their positions with acetonitrile alone with some loss of peak sharpness, except for the six discernable most hydrophobic components which improved in shape. Propanol alone gave comparable recoveries but inferior resolution compared to the acetonitrile/propanol mixtures.

The relative recovery of rhodopsin under various solvent conditions are presented in Table 1. HPLC of a delipidated bovine rod outer segment (ROS) membrane preparation is shown in Fig. 4; this sample contains only the glycoproteins from the ROS which elute from Con A-Sepharose in $50 \mathrm{~mm}$ Chaps (it is estimated that rhodopsin accounts for 50$80 \%$ of the total protein in bovine ROS (16,23)). Clearly, the ternary solvent system incorporating a mixture of acetonitrile: propanol (2:1) gave better HPLC resolution and recovery of rhodopsin than either system using acetonitrile or propanol alone. Reso- 
TABLE 1

Recovery of Bovine Rod Outer Segment Glycoproteins from Reverse-Phase HPLC

\begin{tabular}{clcc} 
& & \multicolumn{2}{c}{ Relative \% recovery } \\
\cline { 3 - 4 } Column $^{a}$ & \multicolumn{1}{c}{ Solvent } & $\begin{array}{c}\text { Total } \\
\text { glycoproteins }\end{array}$ & Rhodopsin $^{c}$ \\
\hline $5-\mu$ m Vydac $_{18}$ & MeCN & 22 & 0 \\
$5-\mu$ m Vydac $_{18}$ & $1-$ PrOH & 41 & 13 \\
$5-\mu$ m Vydac $_{18}$ & MeCN:1-PrOH 2:1 & 100 & 100 \\
$\mu$ Bondapak $\mathrm{C}_{18}$ & MeCN:1-PrOH 2:1 & 100 & - \\
\hline
\end{tabular}

${ }^{a}$ The Vydac column was $4.6 \mathrm{~mm} \times 5 \mathrm{~cm}$ and the $\mu$ Bondapak column was $3.9 \mathrm{~mm} \times 30 \mathrm{~cm}$. Chromatography conditions as described in Fig. 5.

${ }^{b}$ Based on the sum of the area of all components recovered.

${ }^{c}$ Based only on the area of the rhodopsin component.

lution was strikingly better on the short Vydac C18 support $(4.6 \mathrm{~m} \times 5 \mathrm{~cm})$ than on the longer $\mu$ Bondapak $\mathrm{C} 18$ column $(3.9 \mathrm{~mm} \times 30$ $\mathrm{cm})$. It is intriguing that a number of distinct components detectable at both 214 and 280 $\mathrm{nm}$ were reproducibly resolved from the ROS glycoprotein preparation. Although all of the components have not yet been characterized, the more abundant and most hydrophobic component has been identified as rhodopsin by SDS-polyacrylamide gel electrophoresis and amino acid analysis. The other components may represent different glycoproteins from the ROS; however, since bovine rhodopsin has been shown to contain several oligosaccharides (24), some of the other components may also represent rhodopsin with differences in carbohydrate content. Recently it has been reported that two major forms of frog rhodopsin exist that differ in isoelectric pH (25). Certainly, such polarity differences within the bovine rhodopsin molecule population could also contribute to a multicomponent HPLC profile. Monitoring the chromatography at $360 \mathrm{~nm}$ revealed that rhodopsin appears to at least partially retain its natural ligand during HPLC. In addition to the $A_{360}$ peak coeluting with rhodopsin, two other $A_{360}$ peaks were present with retention times that corresponded to unbound all-trans-retinal and 11-cis-retinal standards; these apparent retinoid peaks did not coelute with any of the other components detectable at 214 or $280 \mathrm{~nm}$.

\section{Alternate Solvents for HPLC of Peptides and Proteins}

Despite care in the workup of large hydrophobic peptides and proteins, some preparations we encountered would not chromatograph reasonably in standard solvent systems such as $0.1 \%$ TFA vs. acetonitrile or propanol. Many of these preparations, if they would dissolve at all, could be run in moderate concentrations of formic acid, e.g., $6 \mathrm{M}$ formic acid/0.13 M trimethylamine ( $\mathrm{pH} 1.5$ ) vs. $4 \mathrm{M}$ formic acid/0.09 $\mathrm{M}$ trimethylaminc in $72 \% 1$ propanol. In this system, even dehemed and denatured cytochrome $P-450 \mathrm{LM}_{4}$, insoluble in dilute aqueous TFA and barely soluble in this buffer after initial solution in $88 \%$ formic acid, chromatographed as a sharp peak, and $\mathrm{LM}_{2}$ could be recovered in good yield even from a column as generally inappropriate for such large and hydrophobic materials as U1trasphere ODS (high load of stationary phase, pore size $100 \AA$ ). The high concentration of formic acid limits absorbance monitoring to $260 \mathrm{~nm}$ and above, but this is usually not an insurmountable problem when working with large molecules. As a precautionary measure against possible formyl esterification that may ensue during vacuum drying of collected frac- 


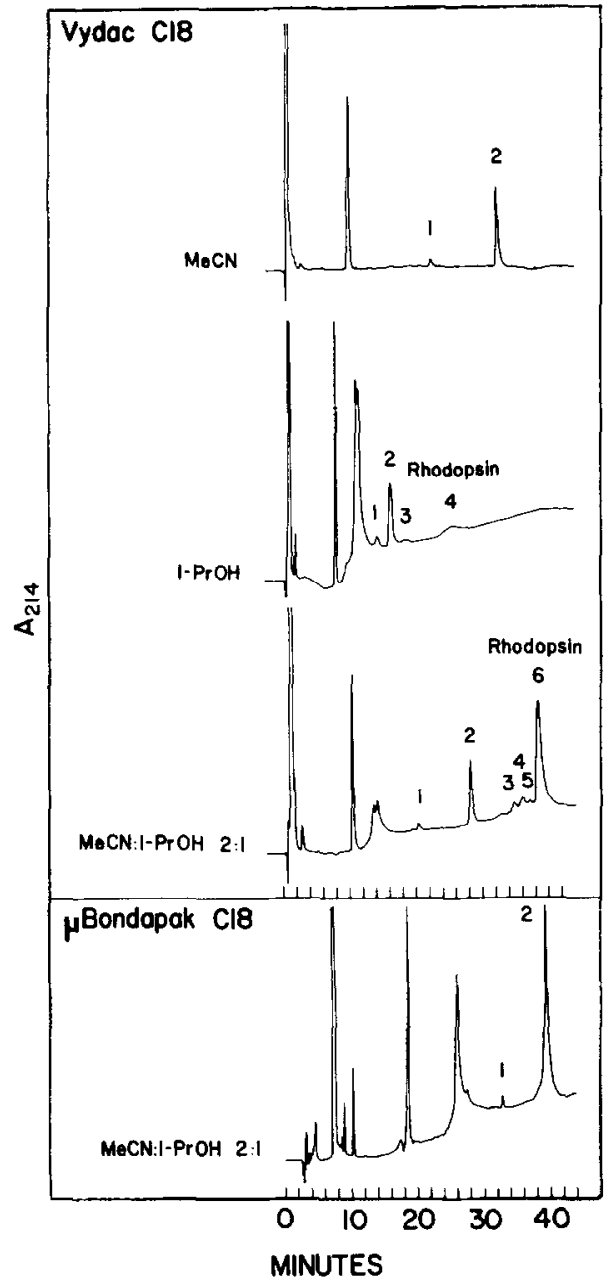

FIG. 4. HPLC of bovine rod outer segment glycoproteins and rhodopsin. About $1.5 \mathrm{nmol}$ of freshly delipidated bovine rod outer segment in $100 \mu$ of $20 \mathrm{nM} \mathrm{Na}$ acetate, $\mathrm{pH} 6.5$, containing $1 \mathrm{mM} \mathrm{MgCl}_{2}, \mathrm{CaCl}_{2}, \mathrm{MnCl}_{2}$, dithiothreitol, $150 \mathrm{mM} \mathrm{NaCl}, 20 \%$ glycerol, and $10 \mathrm{mM}$ Chaps was injected at $0 \%$ organic. Two reverse-phase supports were used: the $5-\mu \mathrm{m}$ Vydac $\mathrm{C}_{18}(4.6 \mathrm{~mm} \times 5 \mathrm{~cm})$ and the $\mu$ Bondapak $C 18(3.9 \mathrm{~mm} \times 30 \mathrm{~cm})$. All eluting solvent contained $0.1 \%$ TFA; the organic components are indicated. The flow rate was $1 \mathrm{ml} / \mathrm{min}$ and the same gradient was employed for all separations: $0-30 \%$ in 1 min starting at 0 time then $30-100 \%$ in $35 \mathrm{~min}$. Absorbance was monitored at $214 \mathrm{~nm}, 1.0$ AUFS. All unnumbered peaks were present in chromatograms developed under identical conditions with blank samples containing only the $\mathrm{Na}$ acetate buffer, salts, glycerol, and detergent (Chaps). Delipidation was by Con A-Sepharose chromatography in Chaps. Total glycoproteins recovered from the Vydac column in MeCN:PrOH 2:1 were distributed as follows (based on area): component 1, 2\%; component 2, 20\%; sum of components 3,4 , and $5,13 \%$; and component 6 , rhodopsin $65 \%$. tions, we routinely treat peptides purified in this solvent with aminoethanol as described in the next section. However, it should be noted that because of the potential hazards of working with formic acid under pressure and the potential for peptide modification, we consider this a solvent of last resort.

Highly acidic peptides such as oxidized and succinylated tryptic peptides often chromatograph poorly in dilute TFA systems because of insolubility due to $\mathrm{pH}$. Attempts to enhance the solubility of hydrophobic peptides through such chemical modification may also result in peptides which do not chromatograph well in standard solvent systems. While such peptides will often chromatograph at neutral $\mathrm{pH}$, few choices exist in buffer systems that are both uv transport and readily volatile at neutrality. A buffer system that has proven effective for us is hexafluoroacetone (HFA, $\mathrm{p} K_{a} 6.6$ ) buffered with ammonia to $\mathrm{pH} 7.2$ ( 0.8 equivalents of $\mathrm{NH}_{4} \mathrm{OH}$ ). Because $\mathrm{HFA}$ hydrates to the stable gem diol in water, there is no uv adsorption due to a carbonyl function, and even $0.1 \mathrm{M}$ solutions may be monitored at $210 \mathrm{~nm}$ or less. A separation of small peptides and oxidized insulin at two ionic strengths using this solvent system is shown in Fig. 5. Others have described the utility of aqueous HFA as a solvent for gel-permeation chromatography of large peptides (26). The enhancement of solubility observed in that case was due to the high concentrations of HFA employed and are unimportant here, where HFA functions only as a buffer. The main defects of HFA are toxicity (27) and unavailability. We emphasize that caution should be exercised in handling this chemical.

\section{Adverse Effects of Formic Acid on Peptides}

Large peptides are commonly generated by chemical methods such as cyanogen bromide cleavage at Met and acid cleavage at Asp-Pro in high concentrations of formic acid. Formic acid is also useful for dissolving relatively insoluble polypeptides, such as large hydrophobic peptides, for further processing during structural analyses. Prompted by the possi- 


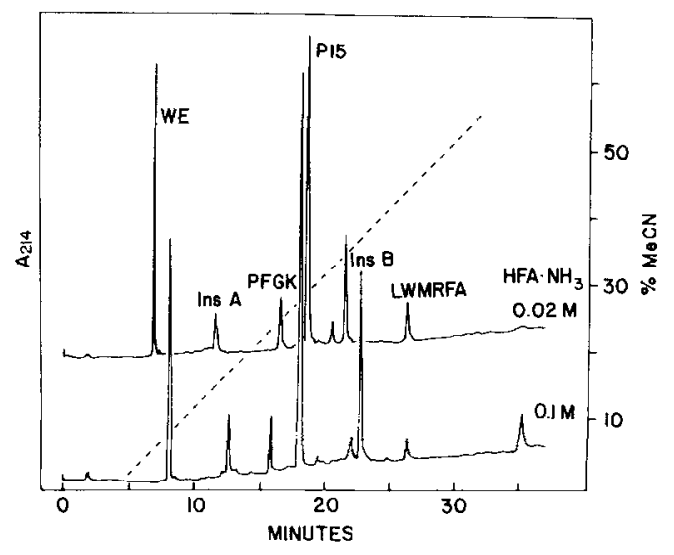

FIG. 5. HPLC scparation of some small peptides and oxidized insulin in hexafluoroacetone/ $\mathrm{NH}_{3} \mathrm{pH} 7.2$ at two ionic strengths. About $0.5-2 \mathrm{nmol}$ of each component was injected at $0 \%$ organic on Ultrasphere ODS and the column developed at $1 \mathrm{ml} / \mathrm{min}$ with a linear gradient of acetonitrile as shown. The molarities indicated are for HFA. Small peptides are given in single-letter codc, and $\mathrm{P} 15$ is a $\mathrm{CNBr}$ fragment of horse cytochrome $c$. Note longer retention of acidic peptides, but not of basic peptides with increased ionic strength.

bility of anomalous side reactions between formic acid and peptides, the effects of formic and some other acids were tested using bovine $\mathrm{Hb}$ as a model system. As shown in Fig. 6, a short exposure to $88 \%$ formic acid ( $20 \mathrm{~min}$ at room temperature) gave no marked effect on the HPLC separation of the $\alpha$ - and $\beta$-chains, although a slight broadening of the peaks was observed. But after $12 \mathrm{~h}$ the peaks were broad, poorly resolved, and clearly more hydrophobic. After 5 days at room temperature, the chromatogram had dramatically changed. A possible explanation for the early peak broadening and increased retention was thought to be formyl esterification of the side change hydroxyl groups of Ser and Thr residues. Attempts to deesterify with the nucleophilic amine, aminoethanol, proved encouraging. The dramatic effect of incubating the 5-day formic acid-treated $\mathrm{Hb}$ in neat aminoethanol for $10 \mathrm{~min}$ at room temperature followed by vacuum drying and HPLC, is shown in Fig. 6. The sharp, regenerated peaks reflect incomplete acid cleavage at the single Asp-Pro bond in each chain. The second of the two sharp peaks seen in the untreated sample has now fused with the first. This probably is the Cterminal fragment from the $\beta$-chain because this region of the $\beta$-chain has no Ser and only one Thr; the analogous portion of the $\alpha$-chain does not appear because it has seven Ser and four Thr (28) and therefore gives a complicated mixture of formylated products exhibiting varying degrees of hydrophobicity. The other Asp-Pro cleavage products in the untreated profile also contain multiple Ser and Thr and are spread out as sets of partially esteritied forms.

The enhanced HPLC resolution of a cyanogen bromide digest of cytochrome $P-450$ $\mathrm{LM}_{2}$ following aminoethanol treatment is shown in Fig. 7. Essentially all peptides were affected by the aminoethanol treatment which generally sharpened resolution and slightly decreased retention times. It should be noted that formic acid can also $\mathrm{N}$-formylate amino

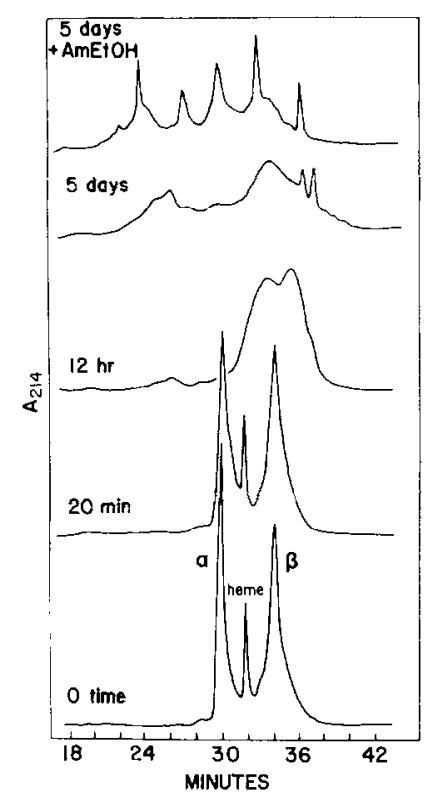

FIG. 6. Deleterious effects of concentrated formic acid on the $\alpha$ - and $\beta$-chains of bovine hemoglobin. Salt-free holohemoglobin was dissolved in $89 \%$ formic acid and left at room temperature; samples were diluted 1:3 with water for injection onto $\mu$ Bondapak $\mathrm{C} 18$. Chromatographic conditions as in Fig. 1. Note peak broadening, increased retention, and decreased resolution with increased exposure to formic acid. Treatment of the 5-day formic acid "Asp-Pro cleaved" hemoglobin with aminoethanol results in regeneration of sharp peaks. 


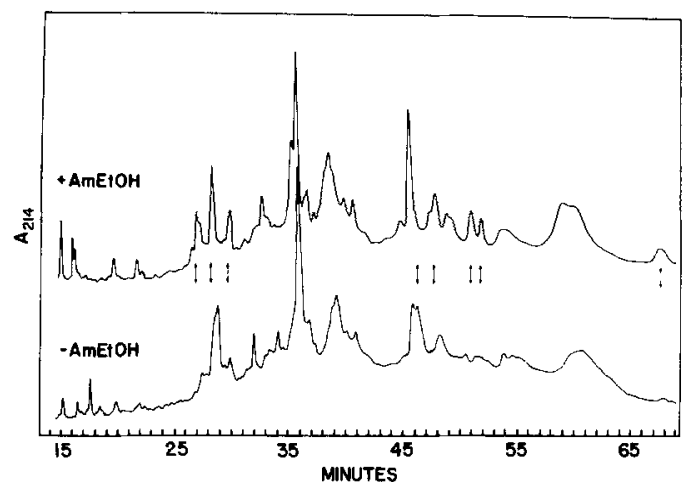

FIG. 7. Comparison of the HPLC resolution of a cyanogen bromide digest of cytochrome $P-450 \mathrm{LM}_{2}$ with and without aminoethanol treatment. The $\mathrm{CNBr}$ digest was performed at room temperature in $70 \%$ formic acid for $30 \mathrm{~h}$. To solubilize the digest before or after aminoethanol treatment, $89 \%$ formic acid was used, but exposure to this solvent was limited by diluting $1: 3$ within $5 \mathrm{~min}$ and storing diluted samples at $0^{\circ} \mathrm{C}$. Note in the treated sample the disappearance of doublets, the generation of new peaks, and the shift of most peaks to slightly shorter retention. These effects are interpreted as deesterification of Ser and Thr residues which were partially formylated under the digest conditions. Chromatography on $\mu$ Bondapak $\mathrm{C} 18$ with acetonitrile as given in Fig. 1 .

groups and react with the indole ring of tryptophan residues, effectively blocking aminoterminal residues and resulting in misidentification of lysine or tryptophan residues (14). Following aminoethanol treatment, none of the peptides isolated from the digest in Fig. 7 exhibited blocked amino-terminal residues by manual sequence analysis (G. E. Tarr, unpublished work).

In other tests, another commonly employed general protein solvent, anhydrous TFA, appeared to esterify $\mathrm{Hb}$ more rapidly than formic acid and the reaction was not entirely reversible with aminoethanol, possibly because of dehydration of Ser and Thr. A third such solvent tested was HFA sesquihydrate which reacted quickly with heme but not to any detectable extent with $\mathrm{Hb}$, even after incubation for weeks at room temperature.

\section{SUMMARY AND CONCLUSIONS}

Large hydrophobic peptides and proteins can pose special problems for HPLC because of limited solubility and tendencies to aggregate and/or stick irreversibly to some reversephase supports. Our results concerning HPLC of the integral membrane proteins cytochrome $P-450$ and bovine rhodopsin may provide useful approaches to reverse-phase chromatography of other hydrophobic polypeptides. The choice of a less retentive support, such as the CN-bonded phase may enhance recovery of large, very "sticky" proteins as we experienced with cytochrome $P-450$ $\mathrm{LM}_{4}$. By incorporating ternary solvent systems into gradient elutions (e.g., dilute aqueous TFA vs. mixtures of acetonitrile and propanol), resolution and recovery of large hydrophobic peptides may be enhanced. Notably, resolution of the $P-450 \mathrm{LM}_{2}$ cyanogen bromide peptides under ternary solvent conditions was improved compared to elution with propanol alone. Ternary solvent conditions provided marked improvement in both the resolution and recovery of rhodopsin compared to elution with either acetonitrile or propanol alone. Attempts to enhance the solubility of hydrophobic peptides by chemical modifications which render the fragments more acidic may preclude chromatography in dilute TFA. Under these conditions the neutral, uv transparent, volatile buffer HFA/ $\mathrm{NH}_{3}$, pH 7.2, may be useful. When all else fails, chromatography of peptides in high concentrations of formic acid may be helpful when used in conjunction with aminoethanol treatment to reverse possible formyl esterifications.

Increasingly, reports in the literature describe the elution of the same peptide in more than one HPLC peak $(6,7,11,29)$. Multiple HFLC peaks containing the same peptide have been attributed to a variety of causes many of which amount to microheterogeneity. Figure 7 illustrates such a situation involving a limited number of peptides apparently suffering from varying degrees of formyl esterification of serine and threonine residues. Spurious amino acid modifications such as oxidations, deamidations, esterifications, or amino group reactions can potentially change the elution position of a peptide. Of course, 
intended derivatizations (such as alkylations and succinylations) which are not quantitative will also result in microheterogeneity. For efficient HPLC, particular care and attention during peptide preparation and storage must be taken to avoid undesirable modifications, especially when working with very small amounts of material.

\section{ACKNOWLEDGMENTS}

J.W.C. owes special thanks to Dr. J. C. Saari for encouragement and support during the course of this work. This study was supported in part by USPHS Grants EY02317, EY-00343, and EY-01730. J.W.C. was supported by Institutional National Research Service Award EY07013. Research by G.E.T. was supported by PHS Grants AM-01339, GM-27558, and NSF Grant PGM 76-14947.

\section{REFERENCES}

1. Walsh, K. A., Ericsson, L. H., Parmelee, D. C., and Titani, K. (1981) Annu. Rev. Biochem. 50, 261284.

2. Hearn, M. T. W. (1980) J. Liq. Chromatogr. 3, 12551276.

3. Mahoney, W. C., and Hermodson, M. A. (1980) J. Biol. Chem. 255, 11,199-11,203.

4. Bohlen, R., and Kleeman, G. (1981) J. Chromatogr. 205, 65-75.

5. Pearson, J. D., Mahoney, W. C., Hermodson, M. A., and Regneir, F. E. (1981) J. Chromatogr. 207, 325332.

6. Bloxham, D. P., Parmelec, D. C., Kumar, S., Wade, R. D., Ericsson, L. H., Neurath, H., Walsh, K. A., and Titani, K. (1981) Proc. Nat. Acad. Sci. USA 78, 5381-5385.

7. Ponstingl, H., Krauhs, E., Little, M., Ade, W., and Weber. R. (1982) in Methods in Protein Sequence Analysis IV (Elzinga, M., ed.), pp. 305-312, Hamana Press, Clifton, New Jersey.

8. Gerber, G. E., Anderegg, R. J., Herlihy, W. C., Gray, C. P., Biemann, K., and Khorana, H. G. (1979) Proc. Nat. Acad. Sci. USA 76, 227-231.

9. Ozols, J., Heninemann, F. S., and Gerard, C. (1980) in Methods in Peptide and Protein Sequence Analysis (Birr, C. H., ed.), pp. 417-429, Elsevier, Amsterdam/New York.
10. Kotake, A. N., and Funae, Y. (1980) Proc. Nat. Acad. Sci. USA 77, 6473-6475.

11. Takagaki, Y., Gerber, G. E., Nihei, K., and Khorana, H. G. (1980) J. Biol. Chem. 255, 1536-1541.

12. Ozols, J., Heinemann, F. S., and Johnson, E. F. (1981) J. Biol. Chem. 256, 11,405-11,408.

13. McKean, D. J., and Bell, M. (1982) in Methods in Protein Sequence Analysis IV (Elzinga, M., ed.), pp. 417-426, Hamana Press, Clifton, New Jersey.

14. Shively, J. E., Pande, H., Yuan, P. M., and Hawke, D. (1982) in Methods in Protein Sequence Analysis IV (Elzinga, M., ed.), pp. 447-454. Hamana Press, Clifton, New Jersey.

15. Haugen, D. A., and Coon, M. J. (1976) J. Biol. Chem. 251, 7929-7939.

16. Papermaster, D. S., and Dreyer, W. J. (1974) Biochemistry 13, 2438-2444.

17. De Grip, N. J., Daemen, F. J. M., and Bonting, S. L. (1980) in Methods in Enzymology (McCormick, D. B., and Wright, L. D., eds.). Vol. 67, pp. 301-320, Academic Press, New York.

18. Gross, E. (1967) in Methods in Enzymology (Hirs, C. H. W., cd.). Vol. 11, p. 238. Academic Press, New York.

19. Hirs, C. H. W. (1956) J. Biol. Chem. 219, 611-621.

20. Tarr, G. E. (1977) in Methods in Enzymology (IIirs, C. H. W., and Timasheff, S., eds.), Vol. 47, pp. 312-357, Academic Press, New York.

21. Tarr, G. E. (1981) Anal. Biochem. 111, 27-32.

22. Jandera, P., Churacek, J., and Colin, H. (1981) $J$. Chromatogr. 214, 35-46.

23. Siebert, F., Schmid, H., and Mull, R. H. (1977) Biochem. Biophys. Res. Commun. 75, 1071-1077.

24. Fukuda, M. N., Papermaster, D. S., and Hargrave, P. A. (1979) J. Biol. Chem. 254, 8201-8207.

25. Fong, S. L., Landers, R. A., and Bridges, C. D. (1981) Fed. Proc. 40, 1842, Abstract 1741.

26. Burkhardt, W. A., and Wilcox, P. E. (1967) Biochem. Biophys. Res. Commun. 28, 803-808.

27. Hexafluoroacetone Product Information Sheet SD240, June 1979, DuPont Company, Elastomer Chemicals Department, Wilmington, Delaware.

28. Dayhoff, M. O. (ed.) (1978) Atlas of Protein Sequence and Structure, Vol. 5, p. 229, Suppl. 3, National Biomedical Research Foundation. Washington, D. C.

29. Henderson, L., Sowder, R., and Oroszlan, S. (1982) in Methods in Protein Sequence Analysis IV (Elzinga, M., ed.), pp. 409-416, Hamana Press, Clifton, New Jersey. 